\title{
EXPLORING QUIZ-STYLE POWERPOINT GAMES AS AN INNOVATIVE E-LEARNING AND TEACHING PEDAGOGY
}

\author{
Nikki Squire, Grand Canyon University
}

\section{ABSTRACT}

Using game-based learning strategies, such as quiz-style PowerPoint games as an e-learning and teaching pedagogy can make a positive impact on how students learn, how they process and retain information, and how they interact with digital media. However, little is known about their impact on students' information literacy development. This quantitative comparative research study examined differences among online freshman students' posttest information literacy (IL) summative scores comparing information literacy (IL) pedagogies (traditional versus quiz-style PowerPoint game) and response to the online formative assessment using the Analysis, Design, Development, Implementation, and Evaluation model combined with the application of the framework as grounded in the behavioral and cognitive learning theories of Bloom's Taxonomy and Sweller's CLT. A comparative analysis using a non-parametric analysis of variance for both hypothesis 1 and 2 indicated no significant difference in IL summative scores between the traditional pedagogy and the quiz-style pedagogy groups ( $p>.05)$, and a significant difference between IL summative scores based on student response for hypothesis 2 ( $p<.05)$. Two recommendations for practice for higher education leadership were (a) to encourage active learning strategies, such as quiz-style PowerPoint games or other game-based pedagogies for teaching and learning for online firstyear writing courses, and (b) to encourage college faculty to use online formative assessments in their classrooms to help increase student participation, interaction, and most of all, course performance.

Keywords: game-based learning, PowerPoint games, online formative assessment, summative assessment, information literacy instruction, information literacy pedagogy

\section{INTRODUCTION}

Faculty teaching in higher education are traditionally responsible for information literacy instruction (ILI) (ACRL, 2016). For instance, college faculty are charged with designing course curricular and assignments, promoting adequate information literacy competencies, fostering student engagement, and assessing student learning (McNicol, 2015; Mullins, 2016; Oakleaf, 2014). Hsieh, Dawson, Hofmann, Titus, and Carlin (2014) and Rosman, Mayer, and Krampen (2016), further concluded that ILI plays a key role in information literacy development. Although review of the literature has provided evidential support for the benefits of ILI, numerous researchers have reported a trend that undergraduate students lack basic information literacy skills (Mazella, Heidel, \& Ke, 2015; Shao \& Purpur, 2016). These concerns, as interconnected with information literacy, critical thinking, reading and writing skills, and issues related to plagiarism, characterize IL problems among today's freshman college students (Mazella et al., 2016; Shao \& Purpur, 2016).

As suggested by Czerkawaski (2014), Loo et al. 
(2016), Margino (2013), and Rosman et al. (2016), one of the main reasons for this limited success is that most ILI sessions or instructional techniques used to teach IL skills are passive in nature, and information is disseminated through lectures, oneshot library sessions, or demonstrations presented by librarians in front of a classroom or screenshot demonstrations by faculty members, which students are unengaged recipients of information. Differences in ILI pedagogies and active-learning techniques may affect student engagement, motivation, working memory capacity, higher order thinking skills, and most of all, student learning (Hsieh et al., 2014; Loo et al., 2016; Rosman et al., 2016). Recently, educators and scholars have investigated the use of active or "deep" learning methods, such as problem-based learning (McBride, 2012), experiential learning (Bliemel \& Ali-Hassan, 2014), serious games (Giessen, 2015), and game-based learning (Cicchino, 2015). These methods challenge students to become active participants in the learning process through engagement with instruction content, self-discovery of information, and learning through trial and error to solve problems, make sound decisions, and create knowledge or meaning of information (Czerkawski, 2014; Loo et al., 2016).

More importantly, game-based learning, such as the use of homemade quiz-style PowerPoint games such as Jeopardy! Wheel of Fortune, and Who Wants to be a Millionaire?, presents a potential solution to facilitate undergraduate student engagement with course content, promoting selfreflection and critical analysis of information, and improving learning outcomes in various academic disciplines offered at traditional campuses, including health sciences or nursing (Aljezawi \& Albashtawy, 2015), accounting (Fratto, 2011), information literacy (Karshmer \& Bryan, 2011), and teaching first-year journalism students basic grammar skills (Burzynski Bullard \& Anderson, 2014). Berk (2011. PowerPoint..., 2011. Research...) and Wanner (2015) provided evidence-based practices for use of PowerPoint to enhance student engagement, encourage interaction and active learning, and increase student comprehension and understanding of course material, and Thornes (2012) noted positive learning outcomes existed for both campus-based postgraduates and distance learners; yet, called for further research to determine whether PowerPoint games are a robust instructional and learning e-pedagogy to improve information literacy skills among e-learners enrolled in a distance learning course. Therefore, it is reasonable to examine whether quiz-style instruction, a game-based learning strategy, impacts students' information literacy development (Gunn \& Miree, 2012; Karshmer \& Bryan, 2011; Wanner, 2015). The research outcomes for this comparative quantitative study may offer an increased understanding of how students process and learn information, which is necessary to determine if differences in ILI pedagogies affect overall student information literacy development. In addition, the results of this study may assist higher education leadership in designing applicable faculty training and development programs, and initiatives and guidelines for delivering ILI pedagogies that promote student success in all academic courses taught face-to-face and online instruction. An overview of current research on PowerPoint games and information literacy instruction in higher education is outlined, as well as a discussion of the research method and design, research findings, and future recommendations.

\section{LITERATURE REVIEW}

The purpose of this quantitative comparative study was to examine whether differences exist in e-learner information literacy development in a mandatory distance IL university course within a four-year university located in Southwest Arizona. Globally, higher education institutions are becoming increasingly concerned about undergraduate students' ability to conduct research and develop strong information literacy skills required in the 21st Century contemporary job market (Gunn \& Miree, 2012; Hsieh et al., 2014; Rendahl \& Kastman Breuch, 2013; Shao \& Purpur, 2016; Weiner, 2014). Scholars, educators, librarians, and game designers have studied various methods for improving information literacy instruction and the influence these methods have on information literacy skills of undergraduate students in online and traditional learning environments. Shao and Purpur (2016), Rendahl and Kastman Breuch (2013), and Hsieh et al. (2014), suggested, through their research on the information literacy skills of college freshmen students at four-year universities, 
that there is a gap between students' connection between information literacy instruction (ILI) and their ability to critically evaluate and comprehend the information.

Thus, the research literature provides an overview of various instruction tools, teaching methods, and online pedagogies suggested by scholars and educators for improving information literacy instruction and student learning, that is, students' information literacy skills, including their critical thinking and problem-solving skills, their proficiency in library search tools and research databases, their writing abilities, as well as their overall performance in a class. More importantly, there are many theoretical abstractions and conceptual frameworks for designing information literacy instruction, measuring and assessing students' information literacy skills, and evaluating the effectiveness of teaching methods in improving learning outcomes within educational contexts. To improve information literacy outcomes for firstyear college students, especially literacy gains for at-risk or underperforming students, gamification can be used as a conceptual framework for pedagogy assessment for e-learning and teaching. Peer-reviewed articles were reviewed to obtain an overview of the differences in information literacy instruction methods and first-year writing pedagogies of first-year students taught by faculty in traditional and online learning environments. The literature reviewed for this review of information literacy instruction was gathered through several research databases as well as associated and relevant professional organizations.

\section{Conceptual Framework}

To consider the study problem, the ADDIE model coupled with the application of the framework, both grounded in behavioral and cognitive learning theories such as Bloom's Taxonomy and Sweller's Cognitive Load Theory (CLT), served as the appropriate conceptual framework for better understanding the role of ILI and student learning. The ADDIE model, a five-step cyclical process for instructional design (ID), is commonly used for both traditional and online instruction and has been around for more than 30 years (Molenda, 2015; Soto, 2013). The five steps are Analysis, Design, Develop, Implement, and Evaluate, and these steps can be easily applied for designing effective online instruction materials and resources for distance learning environments (Easter, Bailey, \& Klages, 2014; Shelton \& Saltsman, 2006), incorporating new technologies in library instruction (Campbell, 2014; Reinbold, 2013), integrating high-impact instructional practices into an online information literacy course (Nichols Hess \& Greer, 2016), and developing an online information literacy curriculum (Mi, 2016). In each empirical study, the ADDIE model was used to promote quality IL instruction, enhance student engagement, increase students' proficiency in information skills, and most of all, improve student learning outcomes.

In fact, Easter et al. (2014) developed an information literacy strategy for distance education students using the ADDIE model of instructional design. Shelton and Saltsman (2006) also used the ADDIE model as a framework for developing strategies or tools for e-pedagogy for online class design, syllabus development, and online teaching. Although Campbell (2014) modified the ADDIE model to align with new technologies for library instruction, the design process remained the same. In addition, Reinbold (2013) utilized the ADDIE model to redesign an evidence-based medicine course taken by first-year medical students. Like Reinbold (2013), Nichols Hess and Greer (2016) employed the ADDIE model to incorporate best practices in teaching and learning into an online, four-credit information literacy course. Mi (2016) also utilized and applied the ADDIE model in developing online information literacy curriculum as an intervention for promoting active learning of information skills and fostering life-long learning through critical reflection among undergraduate medical students.

While Campbell (2014) and Mi (2016) advocated the use of the ADDIE model for information literacy instruction and curriculum design, Mullins $(2014,2016)$ suggested using the IDEA instructional design model for information literacy instruction. The IDEA model, which encompasses the four steps of the instructional design process, Interview, Design, Embed, and Assess, is a library-specific systematic approach in integrating information literacy instruction in traditional academic courses. The purpose of the IDEA model is to increase collaboration between library and academic faculty, whereas, the ADDIE 
model is intended solely for instructional design, including training, instructing, and designing and assessing teaching and learning strategies for all types of learning environments. Although empirical studies show that the ADDIE model is an effective ID for online instruction (Easter et al., 2014; Mi, 2016; Shelton \& Saltsman, 2006), Mullins $(2014,2016)$ noted that the IDEA model more accurately reflects the process of embedding information literacy instructional design within academic disciplines. For this study, IL pedagogy implementation in course design more accurately reflects the instructional design process; therefore, the IDEA model was not considered.

In addition to the ADDIE model for information literacy instruction design, learning theories such as Bloom's Taxonomy (Jayakodi, Bandara, Perera, \& Meedenjya, 2015; Siko, 2013; Weigel \& Bonica, 2014) and CLT (Akgun, Babur, \& Albayrak, 2016; Chang, Liang, Chou, \& Lin, 2017; Rosman et al., 2016) are generally used in higher education to better understand how students learn. For effective instruction and meaningful learning to occur, Khalil and Elkhider (2016) suggested applying appropriate learning theories along with their corresponding instructional design models. Although faculty are heavily involved in the instructional design process, they lack formal training in instructional design models and learning theories (Khalil \& Elkhider, 2016). As a result, the design and delivery of instructional and learning materials are poorly integrated in the course design and insufficient in creating an environment for successful learning outcomes. Therefore, as recommended by Khalil and Elkhider (2016) and Sweller (2015), the ADDIE model-along with CLT, which is based on an understanding of how people learn through cognitive processes through sensory memory, working memory, and long-term memory, and tailoring instruction accordinglywas used in conjunction with Bloom's Taxonomy, an assessment tool used in measuring student learning achievement, and in developing and categorizing exam questions based on cognitive learning levels (Jayakodi et al., 2015).

For example, Jayakodi et al. (2016) created exam questions according to Bloom's Taxonomy as an assessment for improving learning outcomes and student development in a computing and information systems course at Wayamba University, Sri Lanka. To improve the accuracy of the categorization of exam questions and the weights for each category, Jayakodi et al. (2016) used Natural Language Processing (NLP) techniques, WordNet similarity algorithm and cosine similarity algorithm, and found that both WordNet algorithm and the cosine algorithm generated over $70 \%$ accuracy in identifying question categories. This suggests that Bloom's Taxonomy can be an efficient way in classifying exam questions based on levels of achievement (Jayakodi et al., 2016).

Siko (2013) also used Bloom's Taxonomy as a guide for developing and analyzing higherorder questions at a large, Midwestern U.S. high school; however, the purpose of the study was to analyze student generated questions based on Bloom's Taxonomy for the homemade PowerPoint games students created in a previous study (Siko, Barbour, \& Toker, 2011). Siko (2013) found that students who created a game design project for the first time used higher order questions than groups who created games twice; however, the difference was not statistically significant. Lastly, using a quasi-experimental study to develop deep learning using face-to-face group games as an active learning approach, Weigel and Bonica (2014) applied the three primary domains of Bloom's Taxonomy (cognitive, affective, and psychomotor) to help increase Army graduate students' information retention and learning outcomes in a macroeconomics and a health policy class over a course of a semester. Observations of students' inclass actions and student feedback indicated that both games positively impacted students across the cognitive, affective, and physical domains. According to Weigel and Bonica (2014), students who employed game-play exhibited higher levels of the desire to win, which affected learning.

In addition to utilizing Bloom's Taxonomy for assessing information literacy development using quiz-style PowerPoint games as a method of instruction (Siko, 2013), CLT was used to design instruction to support the learning of complex cognitive tasks (Paas \& Sweller, 2012; Sweller, 2015), especially as it related to information processing and e-learning (Wong, Leahy, Marcus, \& Sweller, 2012). According to Sweller (2015), 
as it relates to instructional design, three aspects of human cognition is generally overlooked by educators, and they include: (a) the acquisition of knowledge for cultural reasons; (b) the role of generic-knowledge and domain-specific knowledge in information processing; and (c) the level of instruction through interaction with working memory and long-term memory. The characteristics of working memory-aspects of human cognitive architecture-can be used to devise instructionaldesign. Therefore, instructional duration times, procedures, and delivery method of information should be considered to reduce all sources of extraneous cognitive load, capacity of the working memory (Sweller, 2015). To assist researchers and educators, there are five basic principles in describing human cognition, that is, the natural information processing system and they include: (1) the role of long-term memory in storing information, (2) borrowing and reorganizing information from the long-term memories of others, (3) the process of random mutations that is generated and tested, (4) the narrowing of the amount of information in working memory, and (5) connecting environmental information with stored information to inform practice or action (Sweller, 2015).

Using CLT as the framework for understanding the role of ILI and working memory capacity, Rosman et al. (2016) conducted a longitudinal study on information-seeking knowledge of 137 psychology undergraduates at a large German university. Rosman et al. (2016) compared two different instruction groups and their effect on students' working memory compacity. To measure information literacy gains over four waves (semesters), Rosman et al. (2016) used an information literacy test that was aligned withACRL 2015 framework. In addition to the summative test, students were asked to rate the information literacy instruction methods on 5-point Likert-Scales. To compare the two groups, Rosman et al. (2016) used multi-level modeling and found that curriculumembedded instruction was more effective than library instruction. Students who received library instruction had a high working memory capacity with steeper learning curves than those who used curriculum-embedded instruction. As evident, instruction plays a key role in information literacy development, especially when it is embedded into the respective curriculum (Rosman et al., 2016). Moreover, reducing cognitive load is crucial for the acquisition of information-seeking knowledge. Therefore, Roseman et al. (2016) recommends designing instruction to enhance the usability of information and multimedia features in instructional and learning materials, tutorials, and modules delivered to students.

Akgun et al. (2016) studied and compared the effects of lectures with PowerPoint or Prezi presentations on cognitive load, recall, and conceptual learning with undergraduate students enrolled in a Computer Programming program at Instanbul Medeniyet University. Through several quasi-experiments, Akgun et al. (2016) found through measurement of the Cognitive Load Scale, achievement tests and concept maps, students who received lectures created by Prezi had more conceptual learning and less cognitive load in regard to teaching computer network systems' content. However, recall of the learning material as measured by an achievement test did not significantly differ across groups. While Akgun et al. (2016) compared the effects of lectures with PowerPoint or Prezi presentation on student learning, Chang et al. (2017) studied the effects of game-based learning materials on different kinds of cognitive loads (intrinsic, extraneous, and germane); however, their study focused on whether game-based learning using multimedia improved student learning outcomes and learning experiences in a general education course at a fouryear university. Chang et al. (2017) found through measurements such as an achievement test, flow experience scale, and cognitive load scale, gamebased learning group had significantly lower extraneous cognitive loads and higher germane cognitive loads than the non-game-based learning group (webpage-based learning material). Also, students in the game-based learning group were significantly more engaged, focused, and exhibited self-reliance over their own learning compared to the non-game-based learning group. Nonetheless, there were no significant differences in intrinsic cognitive loads between both groups. As suggested by Chang et al. (2017), an appropriate amount of multimedia presentation lowers cognitive loads and enhances learning achievements. 


\section{Assessing the Effectiveness of Gamification in} Higher Education

Although traditional ILI methods have been used for several decades, empirical studies have shown that these methods are ineffective in improving information literacy proficiencies among college students enrolled in higher education (Hsieh et al., 2014; Loo et al., 2016). Therefore, ILI has become an ongoing discussion due to the complex nature of the subject, a complexity that results from the numerous factors that have been known to cause and/or are associated with ILI and student learning (Gunn \& Miree, 2012; Mazella et al., 2015; Rendahl \& Kastman Breuch, 2013; Shao \& Purpur, 2016). Therefore, there are several definitions in literature that have been used to define ILI, among them is one that defines ILI as involving traditional (passive) and active learning strategies to improve student learning outcomes (Hsieh et al., 2014; Loo et al., 2016). More importantly, gamification for information literacy instruction have become an increasingly popular approach to teaching and learning in higher education.

Smale (2011) defined gamification as lightweight digital applications that apply game elements to the learning context. Examples of gamification can range from commercially produced digital games, information literacy video games, Web-based board games, and non-digital information literacy games such as board, card, pen-and-paper (tictac-toe, word finds, puzzles, or hangman), or dice games (Smale, 2011). As noted by Smale (2011), digital game-based learning (DGBL) is an effective learning and teaching pedagogy for information literacy and library instruction.

Proponents of game-based learning present several supportive arguments for the use of games and simulations for educational purposes. For example, according to a prominent scholar, James Paul Gee (2005, 2007, 2009, 2013), Presidential Professor of Literacy Studies in Education at Arizona State University, game design features play an essential role in facilitating learning. Educational games provide student learners the opportunity to play roles and learn by doing, thus motivating them to make a commitment to accomplish a task (Gee, 2005, 2007, 2009, 2013). Another advantage of utilizing games for learning is that they are interactive, allowing players to perform specific tasks and receive immediate feedback or rewards for performance. Thus, playing the games increases players' intrinsic and extrinsic motivation to compete in the games while promoting social interaction with their peers (Gee, $2005,2007,2009$, 2013). Interactive digital games also encourage risk-taking by allowing players to repeat a task several times until they have mastered it, therefore, increasing cognitive development (Gee, 2005, 2007, 2009, 2013). Other important attributes of game-based learning include the opportunity to provide multiple ways of learning, encourage experimentation and discovery, and foster higherorder thinking skills using instructional scaffolding such as game questions, well-ordered problems, stories, scenarios, or puzzles (Gee, 2007).

In concurrence with Gee's argument surrounding the benefits of game-based learning in improving student-learning outcomes (2005, 2007, 2009, 2013), Day-Black, Merrill, Konzelman, Williams, and Hart (2015) and Squire (2011, 2013) also support the use of games as an innovative teaching-learning strategy. Games are useful in that they provide feedback in the form of learning material, which encourages participation in meaningful and intellectual play, reinforces learning objectives, and increases comprehension of course concepts, thereby enhancing the learning process (Gee, 2005; Squire, 2011). Per DayBlack et al. (2015), the progression of learning or cognitive development that takes place during the learning process is like the educational technique of "scaffolding" mentioned by Gee $(2005,2007)$. In gaming, scaffolding is the process of allowing gamers to progress from one level to the next based on their capability. Day-Black et al. (2015) stated, "Scaffolding provides support, functions as a learning tool, extends the range of the learner, and permits the accomplishment of tasks not otherwise possible" (p. 91). Using two Web-based game simulations as the teaching strategy, Day-Black et al. (2015) reported that undergraduate nursing students enrolled in a nursing health course were more visually engaged and could memorize facts and apply them to problem-based situations.

Most importantly, the benefits of game-based learning may be especially important for the Millennials also known as Generation $\mathrm{Y}$ and the Digital Natives, the cohort born between 1980 and 
1995 during the boom of social media technologies and digital devices. These student learners are considered technologically savvy with using various multimedia tools and thrive on instant gratification or immediate feedback (Emanuel, 2013; Kim, 2015; Smale, 2011; Williams, 2010). In addition to meeting the needs of the "digital" age student learners, educational-based games haven shown to be an effective intervention or assessment tool for student learning (Day et al., 2015; Halverson $\&$ Owen, 2014). For example, many educators have focused their research on the impact of games for improving student learning outcomes in difficult subject areas such as statistics (Arena \& Schwartz, 2014), accounting (Fratto, 2011), information technology (Bliemel \& Ali-Hassan, 2014), biological sciences (Gauthier, Corrin, \& Jenkinson, 2015), and teaching information literacy concepts (Burzynski Bullard \& Anderson, 2014; Fain, 2011). Other studies, however, have used games as a supplemental learning tool especially for underperforming or at-risk students (Giles, 2015). A consistent argument by prominent scholars, educators, and game designers is that games are interactive, engaging, motivating, challenging, and stimulating, which encourages the development of skills beyond the scope of the game.

\section{Game-based Learning Methods for Information Literacy Instruction}

Meta-analyses conducted by Giessen (2015), Margino (2013), and Smale (2011) have shown that game-based learning has become an innovative teaching-learning pedagogical strategy employed at all levels of education. Based on their literature review study of game-based learning, Cicchino (2015), Jabbar and Felicia (2015), and Woo (2014) found that game-based learning can be used as an effective pedagogy assessment for measuring student learning, supporting student motivation, fostering critical thinking, improving cognitive success, and improving performance outcomes for all academic subjects and learning environments. Game-based learning pedagogies include inperson information literacy games, library treasure and scavenger hunts, virtual games (i.e., video games or commercially produced digital games), and hybrid games (comprising both in-person and virtual game elements) (Margino, 2013; Smale, 2011). Smale (2011) and Wanner (2015) described quiz show-style games such as the popular TV game show Jeopardy! as a non-digital information literacy game commonly used effectively in teaching and learning. In fact, Fratto (2011) used PowerPoint games to promote active learning in a managerial accounting course; Webb, Simpson, Denson, and Duthie (2012) used gaming as an informal instructional technique for improving learner engagement and outcomes for geriatric students; and Day-Black et al. (2015) used an interactive game as a teaching-learning strategy for digital nursing students in a community health nursing course. For this study, a quiz-style PowerPoint game was used as an intervention pedagogy compared to a traditional study-guide for improving post-test measures, that is, student information literacy development in an IL distance education university course.

\section{Quiz-style PowerPoint Games as an E-Learning and Teaching Pedagogy}

Burzynski Bullard and Anderson (2014) designed a PowerPoint quiz study game called "I'll Take Commas for \$2000," which resembles the quiz-games such as Jeopardy! and Twenty Questions. Burzynski Bullard and Anderson (2014) used a quasi-experimental design to determine whether students' mastery and retention of basic grammar improves more by playing games than by instruction through a traditional lecture format. Pre-test and post-test scores from grammar tests from two groups of students (game group ( $\mathrm{n}=$ $47)$ vs. traditional lectures and grammar exercises $(\mathrm{n}=45)$ group) enrolled in Beginning Editing classes at a Midwestern journalism college were examined (Burzynski Bullard \& Anderson, 2014)). In addition to pre-and post-test measures, students in all sections of both courses $(n=92)$ took a self-administered survey through Survey Monkey to gauge students' perceptions of learning and performances after the grammar lessons. This study was based on the constructivist theories of cognitive development, which emphasizes social interaction and student-driven knowledge construction as essential to the learning process (Burzynski Bullard \& Anderson, 2014).

Grammar test scores were analyzed using a two-way analysis of variance (ANOVA), which examined the effect of Time (pretest, posttest) and Instruction Type (games, no games) on test 
scores (Burzynski Bullard \& Anderson, 2014). Burzynski Bullard and Anderson (2014) reported no significant difference between the two groups' pretest scores, suggesting that all students had the same basic knowledge of grammar skills at the beginning of the course. A review of the descriptive statistics indicated that all the perception scores appeared to be high. This meant that the students had a positive attitude toward using technological tools for learning, and they believed the Twenty Questions game contributed to their learning (Burzynski Bullard \& Anderson, 2014). Similar to Burzynski Bullard and Anderson (2014), Fratto (2011) designed a quiz-style PowerPoint game using Twenty Questions to promote active learning in a managerial accounting course at Robert Morris University using Blackboard. Responses to a survey regarding students' perception of the Twenty Questions game using a 4-point Likert scale, on average, found the game useful, and they believed the game positively contributed to their learning (Fratto, 2011). Fratto (2011) recommended using quiz-style PowerPoint games as an active learning strategy for promoting meaningful learning for all undergraduate courses.

Likewise, Aljezawi and Albashtawy (2015), Karshmer and Bryan (2011), Simkin (2013), and Webb etal.(2012), developed a quiz-stylePowerPoint pedagogy game like the popular television game show Jeopardy! and used it as a learning and assessment tool for a variety of academic courses. For instance, Aljezawi and Albashtawy (2015) compared students' performance, satisfaction, and retention of knowledge between a Jeopardy!style game format and a didactic lecture format in teaching models of organizing patient care to fourth-year nursing students at $\mathrm{Al}$ al-Bayt University in Jordan. A total of 66 students completed the study, and pretest results showed no significance difference between the two groups in their achievement scores (Aljezawi \& Albashtawy, 2015). However, posttest scores and the retention test for the students in the quiz group scored significantly better than those in the lecture group. In addition, students' responses to a satisfaction questionnaire, a 5-point Likert scale survey, suggested that students were significantly satisfied with the quiz-style game format compared to the lecture format (Aljezawi \& Albashtawy, 2015).
Using Bloom's Taxonomy to create questions and categorize them into four information literacy categories, along with integrating ACRL IL standards for information literacy instruction, Karshmer and Bryan (2011) found that employing a Library Jeopardy! game was an effective formative assessment in assisting students with library navigation. A total of 361 freshman students completed the library session evaluation form and rated the Jeopardy! game as the most useful compared to the videos and library session (Karshmer \& Bryan, 2011). Additionally, Simkin (2013) conducted eight experimental trials in five separate undergraduate information systems classes to determine the effectiveness of using a Jeopardy! quiz-style PowerPoint game in assessing teaching effectiveness and measuring student performance. Using a pre-game and post-game design, Simkin (2013) compared the treatment group (Jeopardy!) and the control group (non-Jeopardy!), and based on matched-pairs test, no significant differences in test scores were found. In addition to the inclass multiple-choice exam to measure the game's teaching effectiveness, Simkin (2013) administered an in-class survey to assess student perceptions of the quiz-game, and most students indicated that the Jeopardy! game was fun. However, due to low response rates, it is difficult to say if students valued the Jeopardy! game or not. These findings demonstrate the need for more empirical studies to identify game features or factors that lead to better learning gains (Simkin, 2013).

Furthermore, to improve learner engagement and outcomes in a geriatrics course at Medical College of Wisconsin in Milwaukee, Webb et al. (2012) used a Jeopardy! quiz-style game show model similar to Karshmer and Bryan (2011) and Simkin (2013); however, Webb et al. (2012) found through paperbased pretests and posttests, graduate students' short and long-term medical knowledge increased significantly with the use of the Jeopardy! game. In addition, based on the student survey, which included Likert scale ratings, students positively rated that the quiz-game added educational value to their learning (Webb et al., 2012). According to Webb et al. (2012), quiz-style PowerPoint games can be used as an effective teaching strategy to promote learning, increase student engagement, and improve student motivation and satisfaction in a course. 


\section{Summary}

On a national level, academic institutions, the U.S. Department of Education (2015), and the American Library Association (2000, 2015), are currently seeking new developments in information literacy assessment, library instruction, and digital media resources to raise the national literacy proficiency levels among college students in higher education. In fact, the U.S. Department of Education (2015) is urging institutions of higher learning to integrate innovative technologies in their classrooms to improve student attendance, retention, and graduation rates. Schools remain slow in adopting these changes due to various reasons such as budget constraints, faculty resistance to make changes, lack of support from administrators for revising the curricula, infrastructure issues or technological barriers, and poor communication and collaboration between stakeholders (Gee, 2007, 2008, 2010,2012; Squire, 2010, 2013). As a result, faculty may resort to traditional methods of delivering information literacy instruction to students, which based on previous empirical studies from the research literature, do not lead to successful learning outcomes (Fain, 2011; Loo et al., 2016).

To develop deep and meaningful learning, active learning strategies have shown to promote learning, increase student engagement, foster critical thinking, encourage problem-solving, support student motivation, and enhance student satisfaction of learning experience in a course (Hsieh et al., 2015; Loo et al., 2016). Active learning strategies for information literacy instruction can include non-digital, in-person, computer-based, and virtual games for various academic courses and students (Margino, 2013; Smale, 2011). To improve information literacy outcomes for firstyear college students, especially literacy gains for at-risk or underperforming students, gamification can be used as a conceptual framework for pedagogy assessment (Day-Black et al., 2015; Gee, 2012; Giles, 2015; Squire, 2013). More specifically, quiz-style PowerPoint games have shown to be an effective teaching-learning strategy for both traditional and online learning formats (Aljezawi \& Albashtawy, 2015; Burzynski Bullard \& Anderson, 2014; Fratto, 2011; Karshmer \& Bryan, 2011; Webb et al., 2012).

\section{METHOD}

A comparative quantitative approach was employed to examine the relationship between ILI pedagogy, formative assessment, and summative assessment of e-learners at a four-year university to determine whether differences exist in student learning outcomes based on ILI pedagogy used to facilitate learning and teaching in a first-year writing course. Using the ADDIE model as the conceptual framework for online instruction (Soto, 2013) and designing online information literacy curriculum (Mi, 2016), the instruction session served as the study intervention to determine whether differences exist between post-test scores in a between-groups design (Jackson, 2012). In addition to utilizing the ADDIE model for ID, the framework, an information literacy model in higher education, was used as a roadmap for designing information literacy instruction and assessing student learning (ACRL, 2015). Quantitative data included student generated response to the ILI pedagogy and IL summative scores awarded during the 2016/2017 academic year from a fouryear university in the Southwest. Two independent variables included ILI pedagogy: Traditional Studyguide Pedagogy (control group) and the Quiz-style PPT Game Pedagogy (intervention group), and the online formative assessment, measured as student-generated response to the ILI pedagogy (Student Response/No Student Response). The dependent variable was student learning, measured by IL summative score from an online information literacy exam, a post-test summative measurement of students' information literacy skills, which is auto-generated and archived in the online Learning Management System (LMS) maintained and housed by the university.

\section{Population and Sample}

The target population for this study was the estimated 3,000 e-learners enrolled in an information literacy course at a four-year university in the Southwestern state. The sampling frame for e-learners was the full-time faculty roster of six course sections of approximately 125 undergraduates e-learners in the 2016/2017 academic year. In addition, posttest scores and student generated responses to the ILI pedagogy from the sampling frame of e-learners and courses in the 2016/2017 was also collected through 
the online LMS. Posttest information literacy scores based on ILI pedagogy used in the online classroom for the e-learners sampled provided the opportunity to state the effectiveness of the said ILI pedagogy and linked to online formative assessment in fully addressing ILI methods used in higher education, more specifically, ILI pedagogies in first-year writing courses in both traditional and online classrooms.

\section{Data Collection}

Three study variables (a) IL summative score, (b) online formative assessment response, and (c) ILI pedagogy (traditional versus quiz-style instruction) was collected as quantitative data using random sampling (Leedy \& Ormrod, 2010) from the online LMS. Final quiz scores awarded as well as the online formative assessment responses were collected from the institution's LMS from the teaching faculty roster for the sampling frame of the 2016-2017 academic year. Data collection consisted of quantitative data (Cozby \& Bates, 2012), so the number of faculty, courses and final quiz scores, and students included in the sampling frame were static. Data collected was coded to avoid direct identification of the students selected for the study. Student personal identifiers such as student names and student identification number assigned by the university were removed from the dataset and properly coded by CIRT.

\section{Data Analysis}

To ensure accuracy of the F-statistic, the assumption of normality must be met, that is, the data must be normally distributed (Field, 2009); therefore, prior to hypothesis testing, the (K-S) test was used in SPSS to assess normality to ensure data are normally distributed and appropriate for parametric ANOVA (Field, 2009). In addition to using descriptive statistics, Levene's test (1960) was conducted prior to hypothesis testing to ensure that the assumptions of homogeneity of variance was not violated, that is, sample sizes are equal for both instruction groups. To analyze and examine the relationship between the variables, a non-parametric ANOVA statistical test was conducted to provide accurate findings. The main effects and interaction effects demonstrated how inferences can be drawn between the variables (Jackson, 2012). Analysis of data was performed with the results being used to help to identify causal relationships that exists between the chosen variables and facilitate the process of answering the outlined research question and hypotheses. SPSS software was used to analyze the study variables. The $\alpha$-level (significance level) was set at 0.05 . Descriptive statistics (mean, standard deviation, mode, and frequencies) were used for the study variables, as well as inferential statistics to measure the difference between the summative posttest scores and online formative assessment responses among the study groups (Jackson, 2012; Leedy \& Ormrod, 2010). These analysis methods have been used in the prior research on ILI methods used in first-year writing courses and their impact on student learning or academic performance in a course (Hsieh et al., 2014; Loo et al., 2016).

Descriptive statistics was used as a first analysis to describe the data set using frequency and measures of tendency. To further address the research questions, inferential analysis using a non-parametric ANOVA statistical test was used for hypothesis testing to check for any significant difference between the two study groups (Field, 2009). To ensure that the F-statistic is a reliable test, data must be normally distributed, that is variances in each instruction group needs to be comparable, observations should be independent, and the dependent variable must be measured at the interval scale (Field, 2009). Prior to hypothesis testing, a Kolmogorov-Smirnov (K-S) test was conducted to ensure that data in the sample is normally distributed, that is, data is comparable. In addition, to control for Type I and Type II errors, that is, ensure equal sample sizes and group variances, a Levene's test (1960) was conducted as Jackson (2012) pointed to the benefits of using nonparametric statistics when the data is not normally distributed; therefore, a non-parametric ANOVA was suitable for analysis as data requires comparison of two independent variables using different participants in a non-normal distribution on a linear scale (Field, 2009; Jackson, 2012). Lastly, a non-parametric ANOVA is similar to an ANOVA in that it allows testing for differences between means and whether a general linear model, as quantification of the relationship between the independent and dependent variables (Field, 2009).

\section{RESULTS}

The quantitative data collected for this study 
provided information on IL summative scores based on ILI pedagogy used by full-time faculty in addition to student-generated response to the ILI pedagogy, that is, the online formative assessment posted by the full-time faculty for the 2016-2017 academic year. A non-parametric ANOVA analysis was conducted using Kruskal Wallis to determine whether differences existed between the two instruction groups (Field, 2009; Jackson, 2012). The results are presented by research question and associated hypothesis.

\section{Research Question 1/Hypothesis 1.}

RQ1. Do significant differences exist in students' IL summative score of e-learners who received traditional IL instruction compared to e-learners who received quiz-style instruction in a first-year distance learning IL university course?

H10. There was no significant difference in students' IL summative score between e-learners who received traditional IL instruction compared to e-learners who received quiz-style game instruction.

H1A. There was a significant difference in students' IL summative score between e-learners who received traditional IL instruction compared to e-learners who received quiz-style game instruction.

A descriptive analysis was conducted to determine measures of central tendency prior to hypothesis testing. The variables for the study included ILI pedagogy (traditional study guide and quiz-style PowerPoint game), and mean IL summative score (0-50) (see Table 1). Thus, suggesting that most e-learners performed above average $(\mathrm{M}=44, \mathrm{SD}=4.389)$ on the post-test information literacy quiz.

Table 1. Descriptive Analysis: Mean IL Summative Score (0-50)

\begin{tabular}{|c|c|c|c|c|c|}
\hline ILI Pedagogy & M & Md & SD & Range & Var \\
\hline $\begin{array}{c}\text { Traditional Study } \\
\text { Guide }\end{array}$ & 44.02 & 45.14 & 4.794 & 25 & 22.986 \\
\hline $\begin{array}{c}\text { Quiz-style } \\
\text { PowerPoint Game }\end{array}$ & 44.80 & 45.83 & 3.951 & 17 & 15.610 \\
\hline
\end{tabular}

Note. $N=125$.
To examine research question 1, a nonparametric ANOVA was conducted, and the findings indicated no significant difference in IL summative scores between the traditional pedagogy and the quiz-style pedagogy groups (see Table 2). Therefore, the null hypothesis could not be rejected, and no evidence was found to support the alternate hypothesis.

Table 2. Non-Parametric ANOVA Analysis: IL Summative Scores Based on ILI Pedagogy

\begin{tabular}{|c|c|c|c|c|c|}
\hline ILI Pedagogy & $\mathrm{N}$ & $\begin{array}{c}\text { Mean } \\
\text { Rank }\end{array}$ & $\mathrm{df}$ & $\mathrm{H}$ & $\mathrm{p}$ \\
\hline $\begin{array}{c}\text { Traditional Study } \\
\text { Guide }\end{array}$ & 62 & 60.29 & 1 & .698 & .403 \\
\hline Quiz-style Game & 63 & 65.67 & & & \\
\hline Total & 125 & & & & \\
\hline
\end{tabular}

Note. $N=125$.

Research Question 2/Hypothesis 2.

RQ2. Do significant differences exist between students' online formative assessment response for e-learners who received traditional IL instruction compared to e-learners who received quiz-style instruction in a first-year distance learning IL university course?

H20. There was no significant difference between students' IL summative score and students' online formative assessment response between e-learners who received traditional IL instruction compared to e-learners who received quiz-style game instruction.

H2A. There was a significant difference between students' IL summative score and students' online formative assessment response between e-learners who received traditional IL instruction compared to e-learners who received quiz-style game instruction.

A descriptive analysis was conducted to determine measures of central tendency prior to hypothesis testing. The variables for the study included mean IL summative score (0-50) and response to the online formative assessment (no response/response) (see Table 3). Thus, suggesting that e-learners who did not respond to the online formative assessment scored an average of 41 on 
the information literacy quiz, whereas e-learners who did respond to the online formative assessment scored an average of 47 .

Table 3. Descriptive Analysis: Mean IL Summative Score Based on Response to the Online Formative Assessment

\begin{tabular}{|c|c|c|c|c|c|}
\hline $\begin{array}{c}\text { Online Formative } \\
\text { Assessment }\end{array}$ & M & Md & SD & Range & Var \\
\hline $\begin{array}{c}\text { No Student } \\
\text { Response }\end{array}$ & 41.26 & 41.67 & 3.918 & 21 & 15.348 \\
\hline Student Response & 47.72 & 47.22 & 1.391 & 4 & 1.934 \\
\hline
\end{tabular}

Note. $N=125$.

To examine research question 2, a nonparametric ANOVA was conducted, and the findings indicated a significant difference between IL summative scores based on student response (see Table 4) $(\mathrm{H}=91.99 ; \mathrm{p}<.05)$. Therefore, the null hypothesis was rejected, and the alternative hypothesis was accepted, as support existed for the alternative hypothesis.

Table 4. Non-Parametric ANOVA Analysis: IL Summative Scores Based on Student Response to the Online Formative Assessment

\begin{tabular}{|c|c|c|c|c|c|}
\hline $\begin{array}{c}\text { Online Formative } \\
\text { Assessment }\end{array}$ & N & $\begin{array}{c}\text { Mean } \\
\text { Rank }\end{array}$ & Df & H & p \\
\hline $\begin{array}{c}\text { No Student } \\
\text { Response }\end{array}$ & 64 & 32.88 & 1 & $91.99^{*}$ & .000 \\
\hline Student Response & 61 & 94.61 & & & \\
\hline Total & 125 & & & & \\
\hline
\end{tabular}

Note. $N=125 ;{ }^{*} p<.05 ;$ no response/response.

Results may be limited as student learning outcomes in a first-year writing distance education course varies from one academic institution to another and may not reflect other areas of English composition courses; yet, results may be generalizable to similar populations. The study results were also limited to one online Learning Management System (LMS) used in online courses and faculty teaching the selected course.

\section{DISCUSSION}

The key findings of this study suggested that the ILI pedagogy used to facilitate teaching and learning in the selected course did not have a significant effect on student learning outcomes. Results of a non-parametric ANOVA for hypothesis 1 indicated no significant difference in IL summative scores between the traditional pedagogy and the quiz-style pedagogy groups ( $p$ $<.05$ ). For hypothesis 2 , a significant difference in IL summative scores were found between student response (response/no response) to the online formative assessment $(\mathrm{p}<.05)$.

\section{Research Question/Hypothesis 1}

Research question 1 examined differences in IL summative scores based on ILI pedagogy used to facilitate teaching and learning in a first-year writing distance education course, and no significant difference was identified for 125 e-learners. The first implication of hypothesis 1 was that e-learners may have benefited from both ILI pedagogies (traditional versus quiz-style PowerPoint game) because e-learners scored above average $(\mathrm{M}=44$, $\mathrm{SD}=4.389$ ) on the post-test information literacy quiz. Because e-learners scored consistently the same, it remains unknown whether customized Jeopardy! quiz-style PowerPoint games are better games for ILI than other game-based learning methods, such as video games (Squire, 2013), Webbased games (Markey et al., 2008), or interactive online tutorials (Gonzales, 2014), and whether or not these games are better played in information literacy courses or other academic courses (Simkin, 2013; Thornes, 2012).

\section{Research Question/Hypothesis 2.}

Research question 2 examined student response to the ILI pedagogy, that is, the online formative assessment posted by the faculty to facilitate teaching and learning and its impact on student learning outcomes. A significant difference was found between e-learners' response to the online formative assessment and their IL summative score on the post-test IL quiz despite ILI pedagogy used in the selected course. The first implication of this finding was that when students were given the opportunity to respond to an online formative assessment in an online LMS, their IL summative assessment score improved significantly (Haber \& Mitchell, 2017). For example, e-learners who did not respond to the online formative assessment scored an average of 41 on the information literacy quiz; whereas, e-learners who did respond to the online formative assessment scored an average 
of 47; therefore, this suggested application of an online formative assessment in online education may play a critical role in the educational process by allowing the faculty to monitor students' progress as a way of evaluating students' knowledge and comprehension of course concepts in relations to the learning objectives (Perera-Diltz \& Moe, 2015; Rodrigues \& Oliveira, 2014).

The second implication of the hypothesis 2 finding was that posting some form of online assessment or announcement allowed faculty to provide post-assessment feedback to guide students' learning strategies (Zlatovic, Balaban, \& Kermek, 2015); therefore, improved student learning outcomes for undergraduate students remains a top priority in American higher education systems in order to promote adequate levels of information literacy skills based on the new framework for Information Literacy for Higher Education (Association of College and Research Libraries (ACRL), 2016; Oakleaf, 2014). The final implication was that use of a formative assessment may be an essential assessment tool for student learning in a traditional sophomore writing course (Barefoot, 2017), in an online first-year writing course (Haber \& Mitchell, 2017), or an intervention tool for assisting underperforming undergraduate journalism students in mastering English grammar skills (Burzynski Bullard \& Anderson, 2014) thereby suggesting that regardless of ILI pedagogy used in the selected course, e-learners performed significantly higher when given the opportunity to provide feedback on a formative assessment (Zlataovic et al., 2015).

The study finding from hypothesis 2 also contributed to the conceptual framework in that providing an online formative assessment can aid in the creation of comprehension and knowledge (Hooshyar et al., 2016; Tsai, Tsai, \& Lin, 2015) as the connections in an online classroom are reliant on formative assessments; therefore, leading to faculty and student success (Perera-Diltz \& Moe, 2015; Rodrigues \& Oliveira, 2014). Due to the growth of online first-year writing courses and the call to improve IL outcomes for undergraduate students (ACRL, 2016; U.S. Department of Education, 2015), a five-step process for instructional design, such as the Analysis, Design, Development, Implementation, and Evaluation
(ADDIE) model, was essential in integrating core IL competencies based on the newly published framework (Mi, 2016), and applying Bloom's Taxonomy was fundamental in developing higher order thinking questions to guide student learning for exam questions (Jayakodi et al., 2016) and active learning strategies using quiz-style PowerPoint games (Siko, 2013). In addition, the Cognitive Load Theory (CLT) was useful to better understand whether e-learners processed and retained information to support learning based on the instructional design of the ILI pedagogies (Sweller, 2015; Wong et al., 2012); thus, findings contributed to the conceptual framework for providing quality ILI and promoting active learning in an online information literacy course.

\section{FUTURE RECOMMENDATIONS}

Two recommendations for practice were for higher education leadership to (a) encourage active learning strategies, such as quiz-style PowerPoint games or other game-based learning methods for teaching and learning for online first-year writing courses (Hsieh et al., 2014; Loo et al., 2016), and (b) to encourage college faculty to use online formative assessments in their classrooms to help increase student participation, interaction, and most of all, course performance (Hooshyar et al., 2016; Tsai et al., 2015). Two recommendations for future research are to conduct a (a) quantitative quasi-experimental study with a between-groups design to determine causality of differences in academic achievement for quiz-style PowerPoint games in other undergraduate academic disciplines in both traditional and online modalities; and (b) quantitative comparative study of the hypothesis 2 finding to examine gaming versus traditional classroom teaching across various academic disciplines for academic performance, satisfaction, and retention of knowledge. 


\section{REFERENCES}

Akgun, O. E., Babur, A., \& Albayrak, E. (2016). Effects of lectures with PowerPoint or Prezi presentations on cognitive load, recall, and conceptual learning. International Online Journal of Educational Sciences, 8(3), 1. doi:10.15345/iojes.2016.03.001

Aljezawi, M., \& Albashtawy, M. (2015). Quiz game teaching format versus didactic lectures. British Journal of Nursing, 24(2), 86-92.

American Library Association. (2000). Information literacy competency standards for higher education. Retrieved from http://www.ala.org/acrl/standards/ informationliteracycompetency

American Library Association. (2015). Framework for information literacy for higher education. Retrieved from http://www.ala. org/acrl/standards/ilframework

Barefoot, M. R. (2017). Student research and intrinsic motivation: Effects of formative assessment and the two-session model of information literacy instruction. Pennsylvania Libraries: Research \& Practice, 5(1), 13-25. doi:10.5195/palrap.2017.140

Berk, R. A. (2011). "PowerPoint engagement" techniques to foster deep learning. The Journal of Faculty Development, 25(2), 45-48.

Berk, R. A. (2011). Research on PowerPoint: From basic features to multimedia. International Journal of Technology in Teaching and Learning, 7(1), 24-35.

Bliemel, M., \& Ali-Hassan, H. (2014). Game-based experiential learning in online management information systems classes using Intel's IT Manager 3. Journal of Information Systems Education, 25(2), 117-124.

Burzynski Bullard, S. B., \& Anderson, N. (2014). "I'll take commas for $\$ 200 "$ : An instructional intervention using games to help students master grammar skills. Journalism \& Mass Communication Educator, 69(1), 5-16. doi:10.1177/1077695813518778

Campbell, P. C. (2014). Modifying ADDIE: Incorporating new technologies in library instruction. Public Services Quarterly, 10(2), 138-149. doi:10.1080/15228959.2014.904214

Chang, C.-C., Liang, C., Chou, P.-N., \& Lin, G.-Y. (2017). Is gamebased learning better in flow experience and various types of cognitive load than non-game-based learning? Perspective from multimedia and media richness. Computers in Human Behavior, 71, 218-227. doi:10.1016/j.chb.2017.01.031
Cicchino, M. I. (2015). Using game-based learning to foster critical thinking to student discourse. Interdisciplinary Journal of Problem-Based Learning, 9(2). doi.org/10.7771/15415015.1481

Czerkawski, B. C. (2014). Designing deeper learning experiences for online instruction. Journal of Interactive Online Learning, 13(2), 29-40.

Day-Black, C., Merrill, E. B., Konzelman, L., Williams, T. T., \& Hart, N. (2015). Gamification: An innovative teaching-learning strategy for the digital nursing students in a community health nursing course. ABNF Journal, 26(4), 90-94.

Easter, J., Bailey, S., \& Klages, G. (2014). Faculty and librarians unite! How two librarians and one faculty member developed an information literacy strategy for distance education students. Journal of Library \& Information Services in Distance Learning, 8(3-4), 242-262. doi:10.1080/153329 OX.2014.945867

Emanuel, J. (2013). Digital native librarians, technology skills, and their relationships with technology. Information Technology \& Libraries, 32(3), 20-33.

Fain, M. (2011). Assessing information literacy skills development in first year students: A multi-year study. The Journal of Academic Librarianship, 37(2), 109-119.

Field, A. (2009). Discovering statistics using SPSS (3rd ed.). Thousand Oaks, CA: Sage Publications.

Fratto, V. A. (2011). Enhance student learning with PowerPoint games: Using twenty questions to promote active learning in managerial accounting. International Journal of Information and Communication Technology Education, 7(2), 13-20. doi:10.4018/jicte.2011040102

Gauthier, A., Corrin, M., \& Jenkinson, J. (2015). Exploring the influence of game design on learning and voluntary use in an online vascular anatomy study aid. Computers \& Education, 87, 24-34. doi:10.1016/j.compedu.2015.03.017

Gee, J. P. (2005). Good video games and good learning. Phi Kappa Phi Forum, 85(2), 33-37. Retrieved from http://www. phikappaphi.org/web/Publications/PKP_Forum.html

Gee, J. P. (2007). What video games have to teach us about learning and literacy (rev. and updated ed.). New York, NY: Palgrave Macmillan.

Gee, J. P. (2009). Theories and mechanisms: Serious games for learning. New York, NY: Taylor and Francis Group.

Gee, J. P. (2010). New digital media and learning as an emerging area and "worked examples" as one way forward. Cambridge, MA: MIT Press. 
Gee, J. P. (2012). Digital games and libraries. Participatory Culture and Learning, 41(1), 66-70.

Gee, J. P. (2013). Digital media and learning: A prospective retrospective. Retrieved from http://jamespaulgee.com/pdfs/ Digital\%20Media\%20and\%20Learning.pdf

Giessen, H. W. (2015). Serious games effects: An overview. Procedia-Social and Behavioral Sciences, 174, 2240-2244.

Giles, K. (2015). No budget, no experience, no problem: Creating a library orientation game for freshman engineering majors. The Journal of Academic Librarianship, 41(2), 170-177. doi:10.1016/j.acalib.2014.12.005

Gonzales, B. M. (2014). Online tutorials and effective information literacy instruction for distance learners. Journal of Library \& Information Services in Distance Learning, 8(1-2), 45-55. doi:1 0.1080/1533290X.2014.898011

Gunn, M. G., \& Miree, C. M. (2012). Business information literacy teaching at different academic levels: An exploration of skills and implications for instructional design. Journal of Information Literacy, 6(1), 17-34.

Haber, N., \& Mitchell, T. N. (2017). Using formative and summative assessment to evaluate library instruction in an online first year writing course. Journal of Library \& Information Services in Distance Learning, 11(3-4), 300-313. doi:10.1080/153329 OX.2017.1324549

Hooshyar, D., Ahmad, R., Yousefi, M., Fathi, M., Horng, S.-J., \& Lim, H. (2016). Applying an online game-based formative assessment in a flowchart-based intelligent tutoring system for improving problem-solving skills. Computers \& Education, 94, 18-36. doi.org/10.1016/j.compedu.2015.10.013

Hsieh, M. L., Dawson, P. H., Hofmann, M. A., Titus, M. L., \& Carlin, M. T. (2014). Four pedagogical approaches in helping students learn information literacy skills. The Journal of Academic Librarianship, 40(3-4), 234-246. doi.org/10.1016/j. acalib.2014.03.012

Jabbar, A. I., \& Felicia, P. (2015). Gameplay engagement and learning in game-based learning: A systematic review. Review of Educational Research, 85(4), 740-779. doi:10.3102/0034654315577210

Jackson, S. L. (2012). Research methods and statistics: A critical thinking approach. Belmont, CA: Wadsworth Cengage Learning.

Jayakodi, K., Bandara, M., Perera, I., \& Meedenjya, D. (2016). WordNet and Cosine similarity based classifier of exam questions using Bloom's Taxonomy. International Journal of Emerging Technologies in Learning, 11(4), 142. doi:10.3991/ ijet.v11i04.5654
Karshmer, E., \& Bryan, J. E. (2011). Building a first-year information literacy experience: Integrating best practices in education and ACRL IL competency standards for higher education. The Journal of Academic Librarianship, 37(3), 255-266.

Kim, B. (2015). Designing gamification in the right way. American Library Association TechSource, 51(2), 29-35. doi. org/10.5860/ltr.51n2

Levene, H. (1960). Robust tests for equality of variances. In I. Olkin, S. G. Ghurye, W. Hoeffding, W. G. Madow, \& H. B., Mann (Eds.). Contributions to probability and statistics: Essays in honor of Harold Hotelling (pp. 278-292). Stanford, CA: Stanford University Press.

Loo, J. L., Eifler, D., Smith, E., Pendse, L., He, J., Sholinbeck, M., . . \& \& Dupuis, E. (2016). Flipped instruction for information literacy: Five instructional cases of academic librarians. The Journal of Academic Librarianship, 42, 273-280. doi. org/10.1016/j.acalib.2016.03.001

Margino, M. (2013). Revitalizing traditional information literacy instruction: Exploring games in academic libraries. Public Services Quarterly, 9(4), 333. doi:10.1080/15228959.2013.84 2417

Markey, K., Swanson, F., Jenkins, A., Jennings, B., Jean, B., Rosenberg, V., . . \& Frost, R. (2008). The effectiveness of a web-based board game for teaching undergraduate students information literacy concepts and skills. D-Lib Magazine, 14(9/10).

Mazella, D., Heidel, L., \& Ke, I. (2015). Integrating reading, information literacy, and literary studies instruction in a threeway collaboration. TLAR, 16(2), 41-53.

McBride, M. F. (2012). Reconsidering information literacy in the 21st century: The redesign of an information literacy class. J. Educational Technology Systems, 40(3), 287-300. doi. org/10.2190/ET.40.3.e

McNicol, S. (2015). Modeling information literacy for classrooms of the future. Journal of Librarianship and Information Science, 47(4), 303-313. doi:10.1077/0961000614526612

Mi, M. (2016). Application of instructional design principles in developing an online information literacy curriculum. Medical Reference Services Quarterly, 35(1), 112-121. doi:10.1080/027 63869.2016.1117298

Molenda, M. (2015). In search of the elusive ADDIE Model. Performance Improvement, 54(2), 40-42. doi:10.1002/ pfi. 21461 
Mullins, K. (2014). Good IDEA: Instructional design model for integrating information literacy. The Journal of Academic Librarianship, 40, 339-349. doi:10.1016/j.acalib.2014.04.012

Mullins, K. (2016). IDEA model from theory to practice: Integrating information literacy in academic courses. The Journal of Academic Librarianship, 42, 55-64. doi.org/10.1016/j. acalib.2015.10.008

Nichols Hess, A. K., \& Greer, K. (2016). Designing for engagement: Using the ADDIE model to integrate high-impact practices into an online information literacy course. Communications in Information Literacy, 10(2), 264-282.

Oakleaf, M. (2014). A roadmap for assessing student learning using the new Framework for information literacy for higher education. The Journal of Academic Librarianship, 40, 510514. doi.org/10.1016/j.acalib.2014.08.001

Paas, F., \& Sweller, J. (2012). An evolutionary upgrade of cognitive load theory: Using the human motor system and collaboration to support the learning of complex cognitive tasks. Educational Psychology Review, 24(1), 27-45. doi:10.1007/ s10648-011-9179-2

Perera-Diltz, D. M., \& Moe, J. L. (2015). Formative and summative assessment in online education. Journal of Research in Innovative Teaching, 7(1), 130-142.

Rendahl, M., \& Kastman Breuch, L. (2013). Toward a complexity of online learning: Learners in online first-year writing. Computers and Composition, 30(4), 297-314. doi.org/10.1016/j. compcom.2013.10.002

Rodrigues, F., \& Oliveira, P. (2014). A system for formative and monitoring of students' progress. Computers \& Education, 76, 30-41. doi.org/10.1016/j.compedu.2014.03.001

Rosman, T., Mayer, A., \& Krampen, G. (2016). A longitudinal study on information-seeking knowledge in psychology undergraduates: Exploring the role of information literacy instruction and working memory capacity. Computers \& Education, 96, 94-108. doi.org/10.1016/j.compedu.2016.02.011

Shao, X., \& Purpur, G. (2016). Effects of information literacy skills on student writing and course performance. The Journal of Academic Librarianship, 42(6), 1-9. doi.org/10.1016/j. acalib.2016.08.006

Shelton, K., \& Saltsman, G. (2006). Using the ADDIE model for teaching online. International Journal of Information and Communication Technology Education, 2(3), 14-26.

Siko, J., Barbour, M., \& Toker. (2011). Beyond Jeopardy and lectures: Using Microsoft PowerPoint as a game design tool to teach science. Journal of Computers in Mathematics and Science Teaching, 30(3), 302-320.
Siko, J. P., \& Barbour, M. K. (2012). Homemade PowerPoint games: Game design pedagogy aligned to the TPACK Framework. Computers in the Schools, 29(4), 339-354. doi:10.1080/07380 569.2012 .734430

Siko, J. P. (2013). Are they climbing the pyramid? Rating studentgenerated questions in a game design project. Canadian Journal of Learning \& Technology, 39(1), 1-14.

Simkin, M. G. (2013). Playing Jeopardy in the classroom: An empirical study. Journal of Information Systems Education, 24(3), 203-210.

Smale, M. A. (2011). Learning through quests and contests: Games in information literacy instruction. Journal of Library Innovation, 2(2), 36-55.

Soto, V. J. (2013). Which instructional design models are educators using to design virtual world instruction? MERLOT Journal of Online Learning and Teaching, 9(3), 364-375.

Squire, K. (2011). Video games and learning: Teaching and participatory culture in the digital age. New York, NY: Teachers College Press.

Squire, K. (2013). Video game-based learning: An emerging paradigm for instruction. Performance Improvement Quarterly, 21(2), 7-36. doi.org/10.1002/piq

Sweller, J. (2015). Working memory, long-term memory, and instructional design. Journal of Applied Research in Memory and Cognition, 5(4), 360-367. doi:10.1016/j.jarmac.2015.12.002

Thornes, S. S. (2012). Creating an online tutorial to support information literacy and academic skills development. Journal of Information Literacy, 6(1), 81-95.

Tsai, F., Tsai, C., \& Lin, K. (2015). The evaluation of different gaming modes and feedback types on game-based formative assessment in an online learning environment. Computers \& Education, 81, 259-269. doi.org/10.1016/j. compedu.2014.10.013

U.S. Department of Education. (2015). Improving adult literacy instruction: Options for practice and research. Literacy and Information Communication System. National Research Council. Retrieved from http://lincs.ed.gov/publications/ NAS_report

Wanner, T. (2015). Enhancing student engagement and active learning through Just-in-Time teaching and the use of PowerPoint. International Journal of Teaching and Learning in Higher Education, 27(1), 154-163.

Webb, T., Simpson, D., Denson, S., \& Duthie Jr., E. (2012). Gaming used as an informal instructional technique: Effects on learner knowledge and satisfaction. Journal of Surgical Education, 69(3), 330-334. doi:10.1016/j.jsurg.2011.10.002 
Weigel, F. K., \& Bonica, M. (2014). An active learning approach to Bloom's Taxonomy: 2 games, 2 classrooms, 2 methods. U. S. Army Medical Department Journal, 21-29.

Weiner, S. A. (2014). Who teaches information literacy competencies? Report of a study of faculty. College Teaching, 62(1), 5-12. doi:10.1080/87567555.2013.803949

Wong, A., Leahy, W., Marcus, N., \& Sweller, J. (2012). Cognitive Load Theory, the transient information effect and e-learning. Learning and Instruction, 22, 449-457. doi:10.1016/j. learninstruc.2012.05.004

Woo, J.-C. (2014). Digital game-based learning supports student motivation, cognitive success, and performance outcomes. Educational Technology \& Society, 17(3), 291-307.

Zlatovic, M., Balaban, I., \& Kermek, D. (2015). Using online assessments to stimulate learning strategies and achievement of learning goals. Computers \& Education, 91, 32-45. 
REFLECTION ARTICLES 